\title{
ASO Visual Abstract: National Utilization of Imatinib in the Management of Resected Gastrointestinal Stromal Tumors
}

\author{
Rachel K. Voss, MD, MPH ${ }^{1}$, Nader N. Massarweh, MD, MPH ${ }^{2,3}$, Yi-Ju Chiang, MSPH ${ }^{1}$, \\ Neeta Somaiah, $\mathrm{MD}^{4}$, Barry W. Feig, MD ${ }^{1}$, and Christina L. Roland, MD, MS ${ }^{1}$ \\ ${ }^{1}$ Department of Surgical Oncology, The University of Texas MD Anderson Cancer Center, Houston, TX; ${ }^{2}$ Center for \\ Innovations in Quality, Effectiveness, and Safety, Michael E. DeBakey VA Medical Center, Houston, TX; ${ }^{3}$ Michael E. \\ DeBakey Department of Surgery, Baylor College of Medicine, Houston, TX; ${ }^{4}$ Department of Sarcoma Medical Oncology, \\ The University of Texas MD Anderson Cancer Center, Houston, TX
}

According to the National Cancer Database (NCDB), $41 \%$ of patients with high-risk gastrointestinal stromal tumors (GIST) were undertreated and $18.8 \%$ of low-risk patients with gastrointestinal stromal tumors (GIST) were overtreated (https://doi.org/10.1245/s10434-021-10141-8). Altogether, nearly $30 \%$ of GIST patients received treatment that was non-concordant with national guidelines.

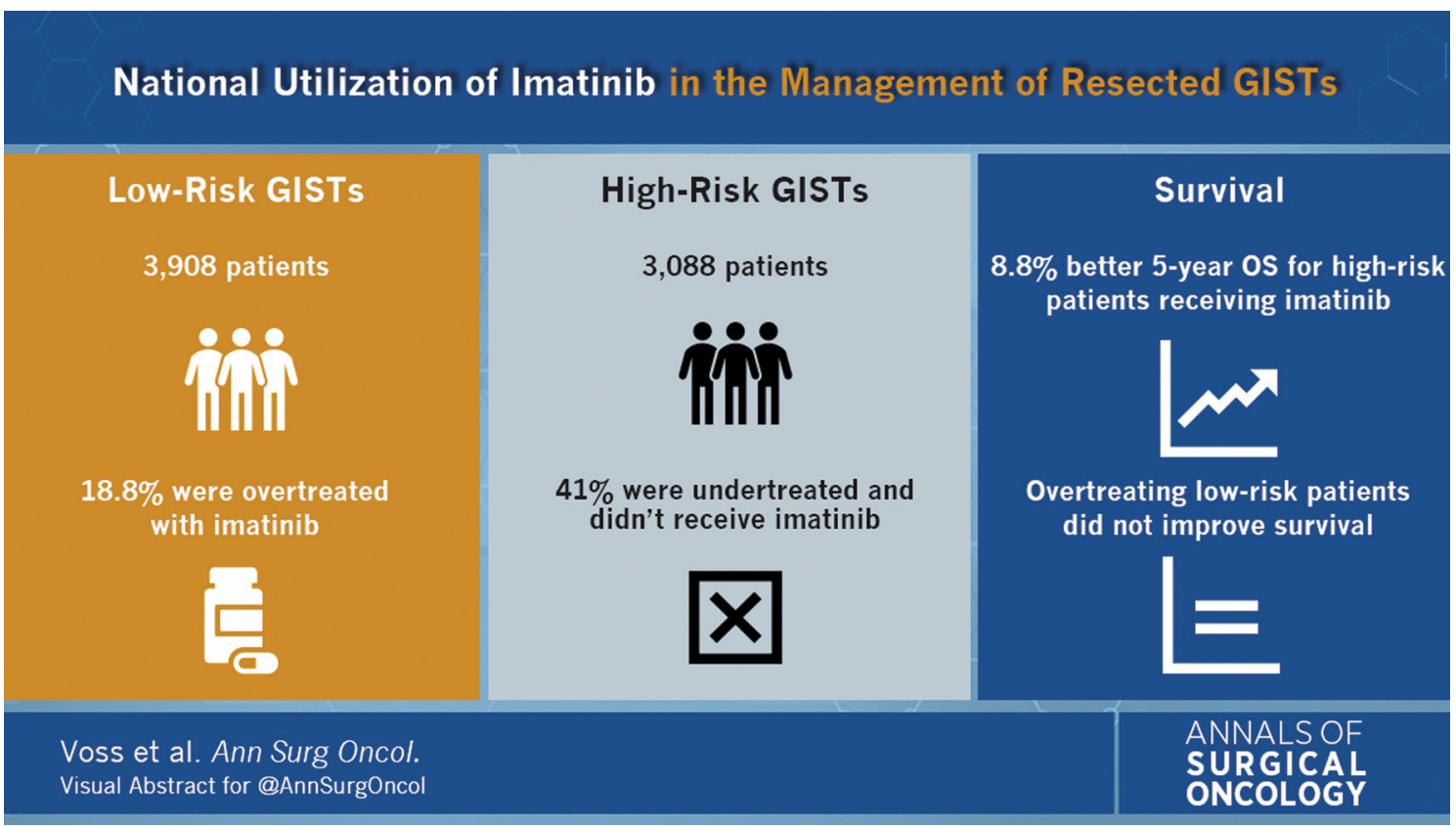

Rachel K. Voss and Nader N. Massarweh have contributed equally.

(C) Society of Surgical Oncology 2021

Published Online: 28 May 2021

C. L. Roland, MD, MS

e-mail: clroland@mdanderson.org
ACKNOWLEDGMENT This study was supported by the Cancer Prevention and Research Institute of Texas, the Department of Veterans Affairs, the Veterans Health Administration, the Office of Research and Development, and the Center for Innovations in Quality, Effectiveness, and Safety (CIN 13-413).

Publisher's Note Springer Nature remains neutral with regard to jurisdictional claims in published maps and institutional affiliations. 